\title{
Gracilaria FEROX J. Agardh, NUEVO TAXON PARA LA ISLA DE Gran CANARIA
}

\author{
Nieves GONZÁLEZ HENRÍQUEZ
}

RESUMEN: Se cita la presencia de Gracilaria ferox J. Agardh para el archipiélago canario y se hace un estudio anatómico morfológico de dicha especie.

Palabras clave: Gracilaria ferox, taxonomía, Canarias.

SUMMARY: The presence of Gracilaria ferox J. Agardh is recorded for the first time in the Canaries Islands. An anatomic-morphological study is undertaken on the species.

Key wotds: Gracilaria ferox, taxonomy, Canaries.

\section{INTRODUCCIÓN}

En la determinación del material ficológico que condujo a la tesis doctoral «Flórula y vegetación bentónica de la playa de Las Canteras» (Gónzalez Henriquez, 1986) se constató la presencia de ejemplares del género Gracilaria que no concordaban con las especies descritas para Canarias.

Una vez determinado el taxon como G. ferox J. Agardh se rastreó el litoral isleño para la localización de otras poblaciones de esta especie.

\section{MATERIAL Y MÉTODO}

La metodología empleada ha sido la clásica para los estudios taxonómicos. Los pliegos se encuentran depositados en el herbario LPA del Jardín Botánico «Viera y Clavijo».

Para el estudio taxonómico de la especie se empleó material fresco de las distintas poblaciones realizándose cortes ultrafinos con un microtomo de congelación para las secciones del talo. 


\section{RESULTADOS}

Se ha realizado un estudio anatómico-morfológico del taxon para lo cual se efectuaron medidas del diámetro y talla del eje principal, células corticales y medulares y cistocarpos (Tabla 1, Gráfica 1). Los resultados concuerdan con los datos descritos por otros autores para esta especie (Chapman, 1963; Cordeiro-Marino, 1977; Lawson y John, 1982; Taylor, 1928, 1960).

\begin{tabular}{lrrrr}
\hline & MINIMA & MEDIA & MAXIMA & $\mu$ \\
\hline TALLA $(\mathrm{cm})$ LONG TALO & 2.70 & 6.04 & 10.00 & \pm 0.53 \\
$0(\mathrm{~mm})$ BASE TALO & 0.65 & 1.00 & 2.00 & \pm 0.07 \\
$0(\mathrm{~mm})$ TALO MEDIO & 1.30 & 1.85 & 3.00 & \pm 0.12 \\
$0(\mu \mathrm{m})$ CEL. CORTICALES & 7.50 & 12.63 & 15.00 & \pm 0.54 \\
$0(\mu \mathrm{m})$ CEL. MEDULARES & 225 & 324 & 425 & \pm 15.14 \\
$0(\mathrm{~mm})$ CISTOCARPOS & 0.7 & 0.99 & 1.30 & \pm 0.04 \\
\hline
\end{tabular}

Tabla 1. Parámetros morfológicos estudiados

Se han encontrado ejemplares estériles, gametófitos femeninos y esporofitos (Lámina 1: a, b. c. d).

La distribución de este taxon (Mapa 1) está localizada, sobre todo, en las costas del Atlántico Oeste mientras que en la parte Este del océano está restringida a las costas de Cameroun, Ghana y Gran Canaria. Todavía no existen más datos sobre la presencia de esta especie en otras islas del archipiélago canario, aunque probablemente se encuentra en alguna de ellas.

En Gran Canaria este taxon se ha localizado en la costa norte y este (Dos Roques, Las Furnias, Boca Barranco, Las Canteras, La Garita), en charcos de plataformas intermareales rocosas expuestas.

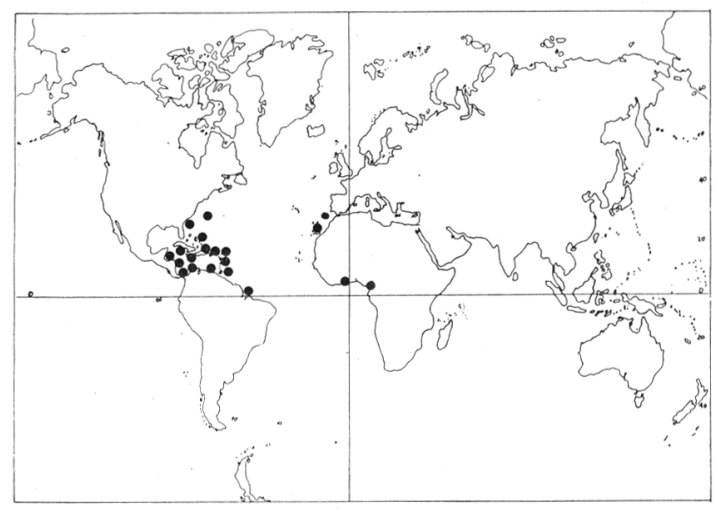

Mapa 1. Distribución mundial de G. ferox J. Agardh 

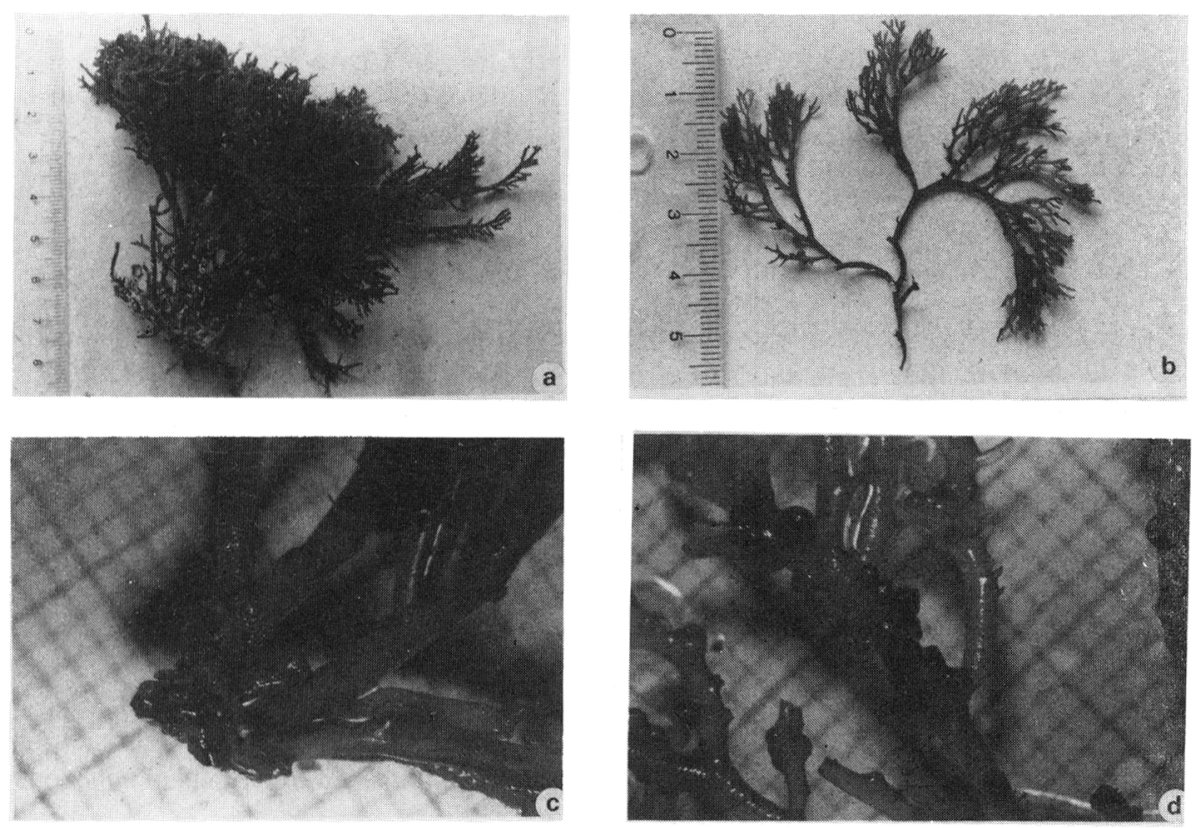

Lámina 1: a) Ejemplar de (G ferox en la fase vegetativa. b) Gametófito femenino. c) Base del talo. d) Ramas con cistocarpos.

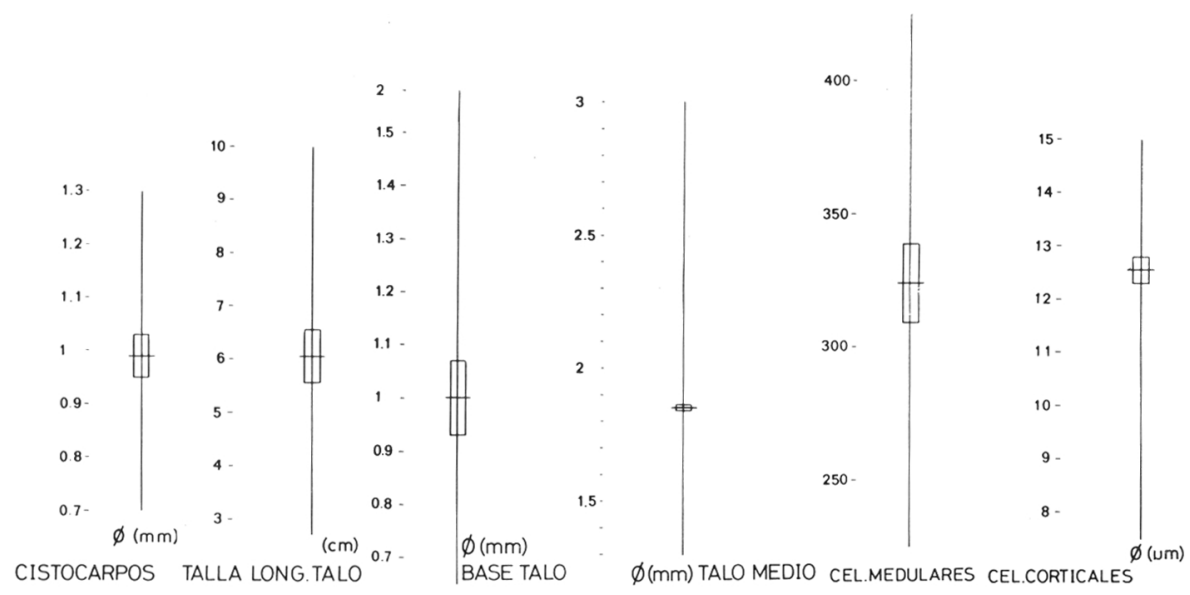

Grálica 1: Representación grálica de los valores del diámetro de los cistocarpos, talla de los individuos, diámetro del talo y diámetro de las células corticales y medulares. 


\section{AGRADECIMIENTOS}

A la Dra. M.C. Gil-Rodríguez por la determinación del taxon y al Dr. Díaz-Piferrer por la certificación de la especie.

\section{BIBLIOGRAFIA}

CHAPMAN, V.J. - 1963- The marine algae of Jamaica. part. 2. Phaeophyceae and Rhodophyceae. Bulletin of the Institute of Jamaica. Science Series, no 12 pt. 2 pag. 105.

CORDEIRO MARINO, M. - 1977- Rodoficeas bentonicas marinhas do estado de Santa Catarina. Rickia, 7:60-61.

GONZALEZ HENRIQUEZ, M.N. -1986- Flórula y Vegetación bentónica de la playa de Las Canteras. Tesis Doctoral (unplubl.) Univ. La Laguna. Tenerife. 257 pp.

LAWSON, G.W.\& D.M. JOHN -1982- The marine algae and coastal environment of tropical west Africa. pag. 218.

TAYLOR, W. \& M. RANDOLPH -1928- The mairne algae of Florida with special reference to the dry Tortugas. Biblioteca Phycologica. J. Cramer. pag. 154.

TAYLOR, W. \& M. RANDOLPH - 1960-Marine algae of the eastern tropical and subtropical coasts of the Americas. Michigan. pags. 444-445.

(Aceptado para su publicación en Junio de 1.990)

Dirección de la autora: Jardín Botánico "Viera y Clavijo" del Excmo. Cabildo Insular de Gran Canaria. Apdo. 14 Tafira Alta. 35017 Las Palmas de Gran Canaria. 